\title{
DIRECT LASER FABRICATION OF INCONEL-718: EFFECTS ON DISTORTION AND MICROSTRUCTURE
}

\author{
Lakshmi Lavanya Parimi, Moataz M. Attallah, J.C. Gebelin and Roger C. Reed \\ School of Metallurgy and Materials, University of Birmingham, Edgbaston, Birmingham, B15 2TT, UK.
}

Keywords: Inconel 718, distortion, laser deposition, texture, precipitation

\begin{abstract}
Limited work is available in the literature on the influence of Direct Laser Fabrication (DLF) on the microstructural homogeneity and the structural integrity (porosity and distortion) of the deposited structures or "builds". These issues are addressed in the current study for Inconel-718 (IN718), focusing on the influence of the tool (deposition) path on the distortion of the substrate, as well as the microstructural development (grain, precipitates and texture). Differing tool paths are shown to have a significant influence on the distortion exhibited; a strategy for optimising the tool paths is suggested. Due to the good weldability of IN718, the builds were crack-free, but there was a minor fraction of volumetric porosity $(\sim 0.02)$, which spatially varied across the build. The microstructural investigations showed that the build has a heterogeneous microstructure, with coarse columnar and equiaxed grains at the bead centre surrounded by fine equiaxed grains at the bead boundary. Electron-Backscattered Diffraction (EBSD) was performed to rationalise the solidification behaviour and texture developed, and any influence of substrate microstructure. It is found that the grain orientation of the substrate has a significant influence on the build as the first few layers are deposited. However, there is no strong texture in the final microstructure. The build displays significant interdendritic segregation which promotes Laves, $\gamma^{\prime \prime}$, Ti and $\mathrm{Nb}$ rich carbides and consequently somewhat lower hardness when compared with wrought IN718.
\end{abstract}

\section{Introduction}

There is a growing interest in the use of direct laser fabrication (DLF) as a repair method or for the production of near net-shape components, particularly for Ni-based superalloys [1]. DLF can also be utilised to add features to an existing cast, machined, or forged structure, in what is commonly referred to as hybrid manufacturing. It can also be used as an economic repair method for repairing worn or damaged parts, with minimum postmachining or stress-relief processes, when compared to replacing the whole component [1]. Accordingly, DLF has a number of advantages, compared to the conventional manufacturing processes, including the reduction in material waste, the design flexibility, as well as the cost saving benefits when using it as a repair method. Furthermore, DLF structures normally have fine microstructures and reduced heat-affected zone, compared to fusion welding processes, in addition to superior mechanical properties compared to the as-cast material properties due to the inherently rapid solidification rates [2, 3].

Although it is possible to optimise the process parameters to produce fully dense structures, the DLF process ultimately produces local changes in the microstructure and structural integrity, due to the thermal fields associated with the process during the solidification of the molten powder. These issues need to be assessed in order to minimise their influences on the component properties.

In practice, the build quality and morphology of laser deposition can be affected by a number of DLF parameters, including the laser power, traverse speed, standoff distance (or laser focal distance), hatch spacing (in plane spacing or bead overlap), layer thickness, tool path, and powder flow rate. Considerable work has been performed to optimise these parameters, in order to obtain a defect-free build with a good surface finish [4-7]. However, only limited work is available on the build/substrate interaction, particularly the microstructure/texture development, and on the mitigation of distortion due to DLF. Due to the local variations in the solidification conditions within the melt pool, the microstructure becomes generally heterogeneous, with varying grain sizes and shapes (columnar and equiaxed), and a complex precipitates structure [8]. Similarly, several thermal management approaches were previously studied to assess their influence on the distortion generated by DLF $[9,10]$. However, only limited work was performed on the use of the tool (deposition) path to control the thermal fields, and accordingly minimise the distortion[11].

The aim of the present investigation is to address some of the aforementioned shortcomings in the DLF literature on the distortion and microstructural homogeneity. IN718 is known to have a good weldability, due to the relatively sluggish $\gamma^{\prime \prime}$ precipitation kinetics, which makes it suitable for DLF [6]. Nevertheless, the exact procedures by which DLF is used to produce minimal distortion in the build and substrate remain unclear. Moreover, the microstructural evolution, in the grain and precipitates structures, as well as the texture, needs further assessment, particularly since the mechanical properties are greatly influenced by it. It equally highlights the need for any post DLF heat treatments to homogenise the microstructure.

\section{Experimental}

\section{$\underline{\text { Material }}$}

Gas atomized IN718 was used in this investigation, with the chemical composition given in Table 1 . The average particle size of the powder is $\sim 60 \mu \mathrm{m}$, with $90 \%$ of the particles falling within the size range of $40-100 \mu \mathrm{m}$, which is the typical range for DLF[6]. The powder is almost spherical in shape with inherent porosity in few particles and very fine satellite particles infrequently attached to the particles, Fig. 1. The microstructure of the particles shows a fine dendritic network, which is caused by the rapid solidification during gas atomization, Fig. 2. 


\begin{tabular}{|c|c|}
\hline Elements & $\mathbf{W t} \%$ \\
\hline $\mathrm{Ni}$ & 53.34 \\
\hline $\mathrm{Cr}$ & 18.2 \\
\hline $\mathrm{Fe}$ & 18.9 \\
\hline $\mathrm{Nb}$ & 5.1 \\
\hline $\mathrm{Mo}$ & 3.1 \\
\hline $\mathrm{Ti}$ & 0.9 \\
\hline $\mathrm{Al}$ & 0.29 \\
\hline $\mathrm{C}$ & 0.025 \\
\hline $\mathrm{B}$ & 0.005 \\
\hline $\mathrm{O}$ & 0.004 \\
\hline $\mathrm{Si}$ & 0.14 \\
\hline
\end{tabular}

Table 1. Chemical composition of IN718 used in this study

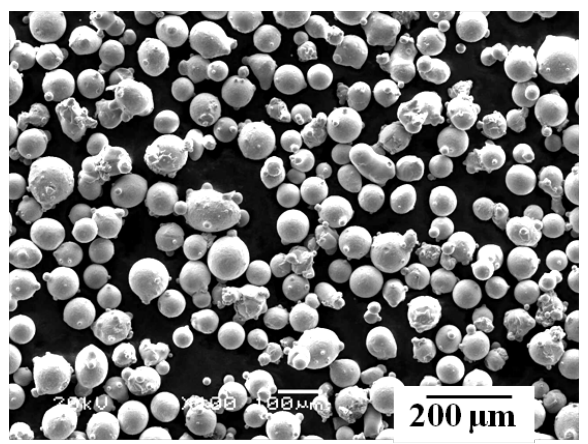

Figure 1. Secondary electron image of gas atomized IN718 Powder.

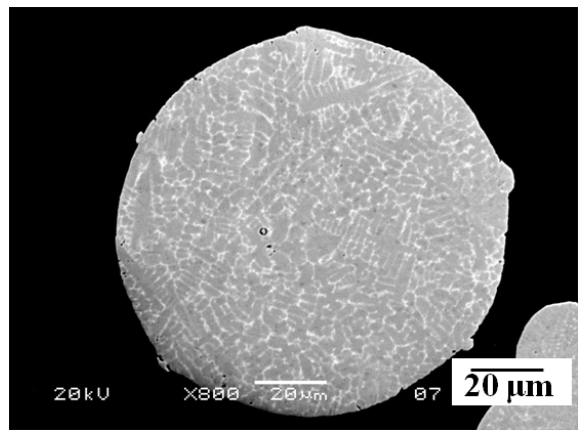

Figure 2. Backscattered electron (BSe) micrograph of powder showing dendritic network.

\section{Laser Deposition:}

Specimens were built using a DLF Quantum system, fitted with a Wegmann-Baasel $1750 \mathrm{~W} \mathrm{CO} \mathrm{CO}_{2}$ laser. The experiments were performed in a controlled argon atmosphere, with $\mathrm{O}_{2}$ level less than $50 \mathrm{ppm}$. The laser beam was focused to a spot size of $\sim 0.5$ $\mathrm{mm}$ using a ZnSe lens with a focal length of $127 \mathrm{~mm}$. A 4- beam nozzle assembly (developed in-house) was used for powder feeding, using argon as a carrier gas at a flow rate of $5.5 \mathrm{l} / \mathrm{min}$.

\section{Distortion and Thermocouple Measurements}

To study the influence of the tool path on the distortion, 3 different tool paths were selected, which represent a longitudinal deposition path (tool path 1), a transverse deposition path (tool path 2), and a combination of both (tool path 3), Fig. 3-a, producing rectangular deposits of size $80 \mathrm{~mm} \times 20 \mathrm{~mm}$ on $4 \mathrm{~mm}$ thick IN718 rolled substrates of size $100 \mathrm{~mm} \times 32 \mathrm{~mm}$. A total of 10 layers were deposited with a hatch spacing of $0.7 \mathrm{~mm}$, meaning that there was no overlap between the successive passes, as shown in Fig. 3-b. The substrates were stress relived at $955^{\circ} \mathrm{C}$ for 1 hour prior to deposition. A number of 1-mm deep holes were drilled along the length of the substrate to embed K-type thermocouples inside for temperature measurement during deposition at a frequency of $10 \mathrm{~Hz}$. The bottom surface of the substrate was laser scanned using Impact1000 coordinate measuring machine (CMM) system before and after deposition. The distortion in the substrate was estimated by comparing both scans using Geomagic Studio software.

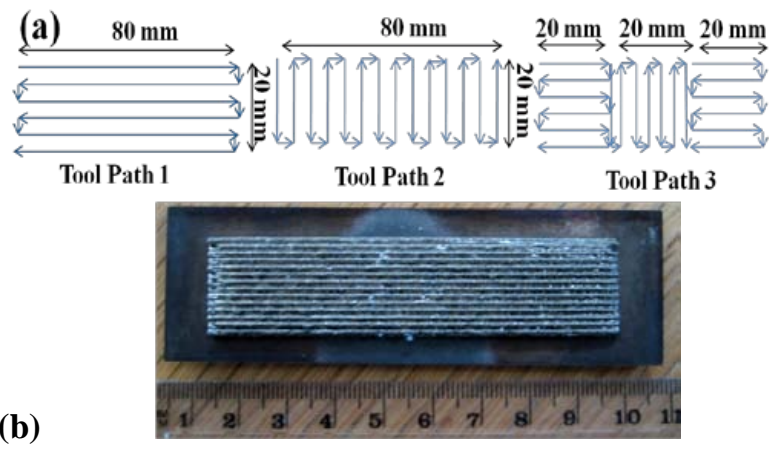

Figure 3. a) The tool paths used, and b) a deposit with tool path 1 .

\section{Microstructural Characterization}

Solid blocks of size $15 \mathrm{~mm} \times 15 \mathrm{~mm} \times 10 \mathrm{~mm}$ were built on a 2 $\mathrm{mm}$ thick substrate, which was cut out from a large cast IN718 block. A square-hatched tool path was used for deposition, Fig. 4a. Optimization studies were performed to obtain a sound build, investigating the influence of the laser power, scan speed, powder flow rate and hatch spacing. A pre scan was performed with the same condition as the build without powder which cleans the substrates from oxides and also roughens the surface in order to help good bonding. An optimum deposition condition was chosen that was comprised of deposition at 558W laser power, 400 $\mathrm{mm} / \mathrm{min}$ scan speed and $7.5 \mathrm{~g} / \mathrm{min}$ of powder flow rate (Fig. 4-b). The optimum condition displayed very limited porosity, with no bonding defects, interfacial or bulk cracks.

The builds were sectioned at mid-section (including the substrate), mounted, ground, and polished to $0.05 \mu \mathrm{m}$ acidified alumina polishing solution. In order to measure the porosity distribution, optical micrographs were taken from the front view (Plane YZ), side view (Plane XZ) and top view (Plane XY) of the polished samples using a Leica ${ }^{\mathrm{TM}}$ DMRX optical microscope, and were later analysed using ImageJ 1.34 software. To reveal the grain and precipitates structures, specimens were electro-etched using a 
$10 \% \mathrm{H}_{3} \mathrm{PO}_{4}$ solution $\left(10 \% \mathrm{H}_{3} \mathrm{PO}_{4}\right.$ and $90 \%$ distilled water, by volume) with a copper cathode for 5 - $10 \mathrm{~s}$ at $5 \mathrm{~V}$.

Grain size measurements were performed using ImageJ to measure the minimum and maximum Feret, and aspect ratio. To analyze the microtexture, electron backscattered diffraction (EBSD) mapping was performed using a FEI-Sirion field emission gun scanning electron microscope (FEG-SEM), equipped with an EBSD detector and HKL Channel 5 software for Kikuchi pattern acquisition and analysis. Energy-dispersive X-ray spectroscopy (EDX) was also performed to analyse the chemical composition of the precipitates. Vickers hardness was measured using a Struers hardness tester, with a $200 \mathrm{~g}$ load sustained for $5 \mathrm{~s}$, on mounted and polished samples. The hardness values were taken across the build at an interval of $0.1 \mathrm{~mm}$.

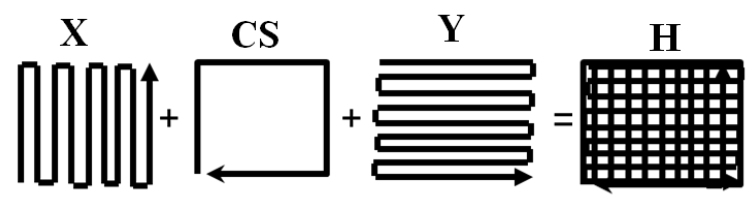

Figure 4. Hatched $(\mathrm{H})$ type laser tool path employed for solid block (15 mm $\times 15 \mathrm{~mm} \times 10 \mathrm{~mm})$ showing the infill tool path in $\mathrm{X}, \mathrm{Y}$ directions with a contour scan (CS)

\section{Results}

The Influence of Tool Path on Distortion

By performing laser scanning for the builds made using the three different tool paths, it was possible to establish a correlation between the tool path and the degree of distortion in the substrate caused by the thermal fields. Comparing tool paths 1 and 2 (Fig. 5 ), it becomes obvious that the distortion is more in the longitudinal direction compared to the transverse direction in the former, whereas the distortion distribution appears to be uniform in both orthogonal directions in the latter. Generally, the distortion appears to be concentrated around the build in all the three cases.

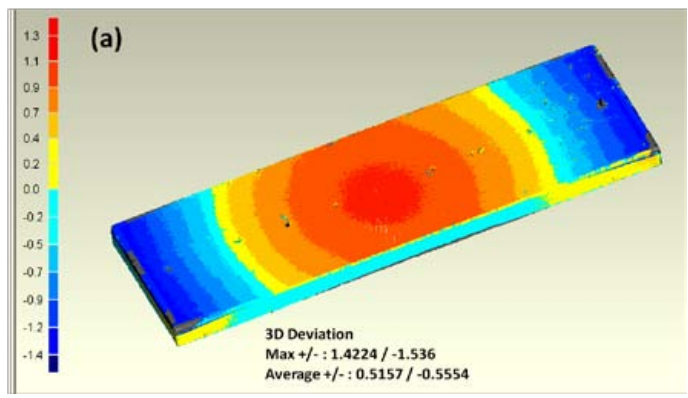

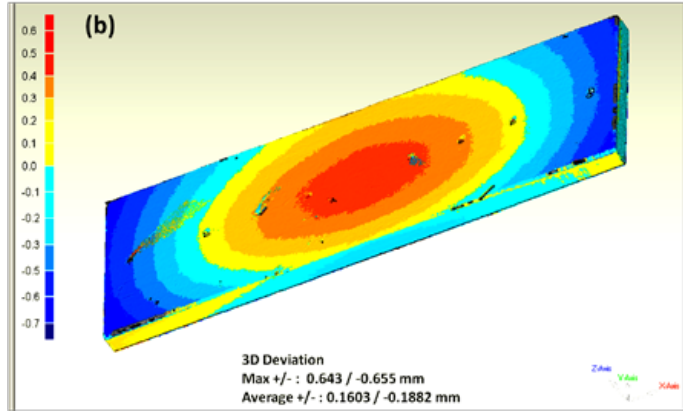

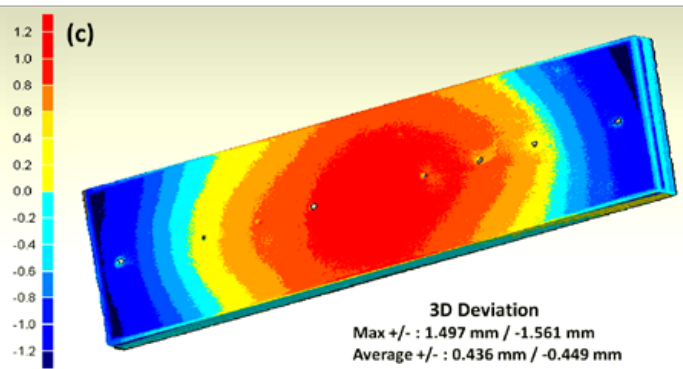

Figure 5. Contour maps displaying the distortion of the substrates after deposition for (a) tool path 1 (b) tool path 2 and (c) tool path 3.

By comparing the three builds, it was found that tool path 2 (transverse filling) resulted in the least distortion from centre to edge in the substrate among the three paths, Fig. 6-a. This was correlated with the cooling rates obtained via the thermocouple measurements for the three deposition strategies, Fig. 6-b. The substrate attained a maximum temperature of around $400{ }^{\circ} \mathrm{C}$ and the thermocouple readings varied between 150 to $400{ }^{\circ} \mathrm{C}$ with variation in melt pool location from them.

By correlating the cooling rates with the tool path, it seem that the tool path 2, which had the most uniform and lowest cooling rate $\left(1{ }^{\circ} \mathrm{C} / \mathrm{s}\right)$ distribution along the length of the substrate, was associated with the minimum distortion. Interestingly, tool path 1 , which led to a relatively uniform, yet higher $\left(\sim 3^{\circ} \mathrm{C} / \mathrm{s}\right)$, cooling rate, was associated with the highest distortion levels obtained at the edge of the substrate.

(a)

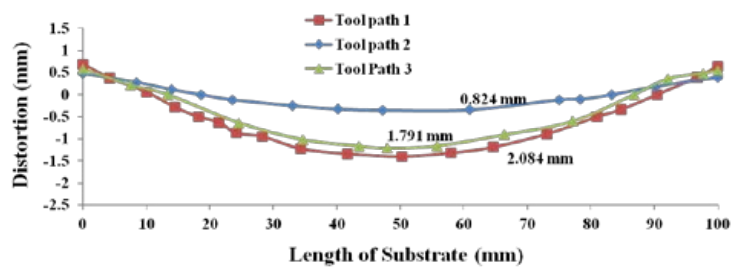


(b)

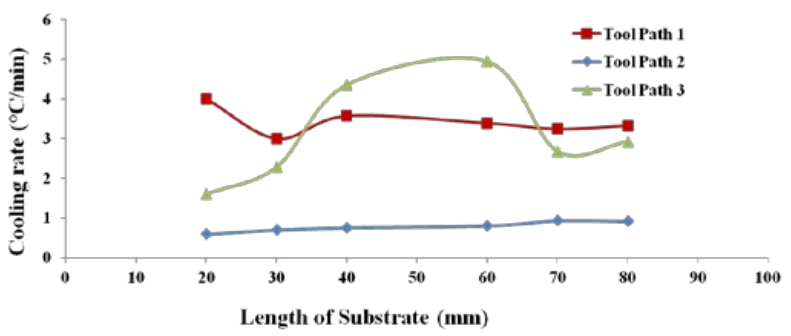

Figure 6. The influence of the tool path on a) the distortion, and b) the cooling rates of the substrate measured at thermocouple locations (both measured at mid-width of the substrate).

\section{Microstructural Characterisation of the Solid Blocks}

\section{Build Macrostructure and Porosity}

The macrostructure of the build resembles the bead-like morphology that is commonly observed in multi-pass welds, Fig. 7. It was observed that the bead size is slightly larger and non uniform at the bottom (close to the substrate) and became more uniform at the top layers, which can be attributed to the rapid cooling rates in the first layers close to the substrate. The top view of the build shows hatched type morphology (Fig 7-b), which is similar to the used tool path (Fig 4).

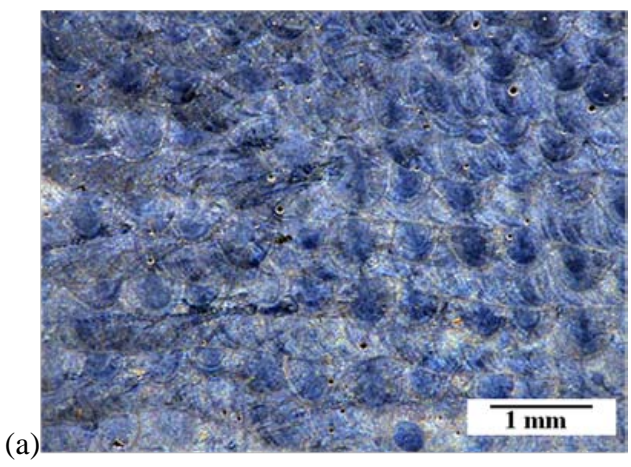

(b)

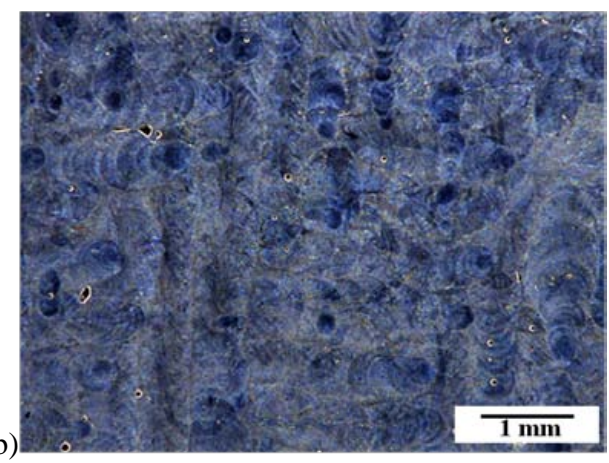

Figure 7. Optical micrographs for the build structure showing (a) Plane YZ and (b) Plane XY.

Image analysis was performed to measure the spatial variation in porosity across the build. The measurements showed that the average porosity fraction only decreased slightly from the bottom to the top of the build, Fig. 8-a. Overall, the average porosity is less than 0.01 ,which is similar to the optimum porosity level obtained by Qi et a.l in IN718 DLF structures[6]. The largest pore size in the bottom layers i.e., near the substrate is around $500 \mu \mathrm{m}$ where as the maximum pore size is around $100 \mu \mathrm{m}$ in the rest of the build. Although there was considerable scatter in the porosity, it was clear that the porosity fraction close to the substrate was the lowest (0.003), which suggests that there is good bonding between the substrate and the build. The reason for this is attributed to the preparatory laser scan without powder. After the first layer, the porosity increased in few consecutive layers, possibly due to the large thermal gradient between the cold substrate, which acts as a heat sink absorbing the heat from the melt pool, leading to poor bonding or high porosity due to rapid or premature freezing of the melt pool giving rise to some un-melted particles. This problem could be alleviated by increasing the laser power and scan speed, while decreasing the powder flow rate in the initial layers. After few layers of deposition when the build is away from the cold substrate the porosity, due to un-melted particles caused by rapid freezing of the melt pool, decreases. Across the build (from edge to edge), the porosity was higher at mid-height and width locations compared to the edge of the build, Fig. 8-b. Due to the hatched tool path, the edges of the build usually stay hotter than the centre, which promotes bonding at the edges.

(a)
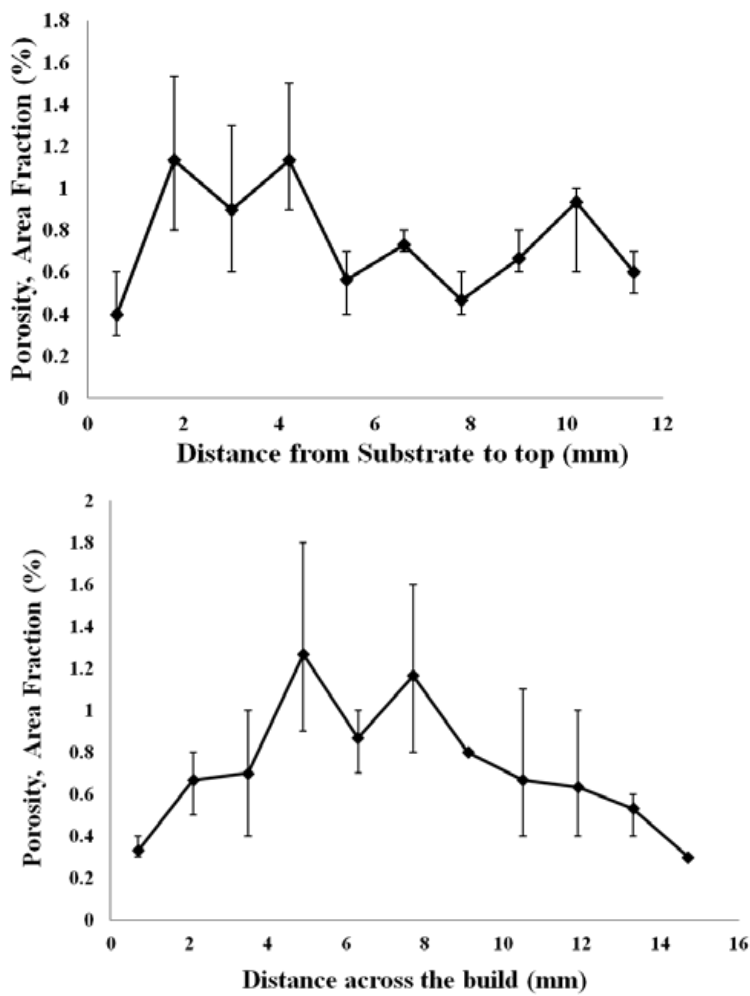

(b)

Figure 8. Spatial variation in porosity (a) along the height of the build (b) across the length/width of the build.

Grain Morphology and Distribution:

Figure 9-a shows the optical micrograph of a single bead taken from the top layers of the build. The bead looks more elliptical 
compared to the bottom layers, which are more circular in nature. The variation in bead shapes can be observed from figure 7-a. It was observed that the dendrites grew epitaxially from the bead boundary to the centre and were mostly contained within the single bead boundary (i.e. within the laser pass), unlike in previous studies where the dendrites traverse to the next layer [12, 13]. The reason for this contradiction could be due to the amount laser power (the heat input) being low in this study, compared to previous work. The dendrites were generally fine, with $5 \mu \mathrm{m}$ arm spacing due to high cooling rates associated with DLF. This was previously observed in IN718 DLF structures [6, 12].

An EBSD map was plotted on the bead which was taken from the lower layers to understand the grain size distribution. There is a bimodal grain size population across the bead which was previously reported by Fencheng Liu et al.[13]. Generally, a single bead can be divided into three regions (Fig, 9-b):

A. Very fine equiaxed region in the bead boundary: mean size of $\sim 5 \mu \mathrm{m}$ (equivalent diameter, $\mathrm{D}_{\mathrm{Eq}}$ ). This region was thicker at the bottom layer, compared to the top layers.

B. Columnar zone from the boundary to the centre: mean size of $\sim 50-100 \mu \mathrm{m}$, with aspect ratio of 2-5.

C. Coarse equiaxed to elongated grains at the centre: mean size of $\sim 10-20 \mu \mathrm{m}$ with aspect ratio of 1-2.

With respect to the grain size distribution (Fig. 10), the maximum grain size at the bottom most layers was very large $(\sim 400 \mu \mathrm{m})$, compared to the subsequent layers $(\sim 100-150 \mu \mathrm{m})$. The average grain size tends to increase from bottom to the top of the build. For the top layers of the build the heat sink is the previously deposited hot build unlike the bottom most layers where the heat sink is the cold substrate. As the heat does not get dissipated much in the top layers, the grains tend to grow slightly larger than the layers below. There is an exception in the first layer due to the pre-scan employed before deposition that makes the substrate hot for that moment and also forms a pit for the molten pool. In the final layer there is no more heat source from the laser and the layer cools down very fast. This is the reason for decrease in the maximum grain size at the topmost layer. The reason for very low mean grain size $(20-30 \mu \mathrm{m})$ is due to very fine grains present at the bead boundary. The mean grain size increases slightly as we go up the build. These fine grains could be un-melted particles which are being sprayed in excess in to the melt pool and the over sprayed powder would have settled on the semi molten surface after the deposition head has moved away. These fine grains were previously observed by Blackwell [2] on the fracture surface of a laser deposit. As we go up the build due to heat accumulation, these un-melted particles would have melted down.
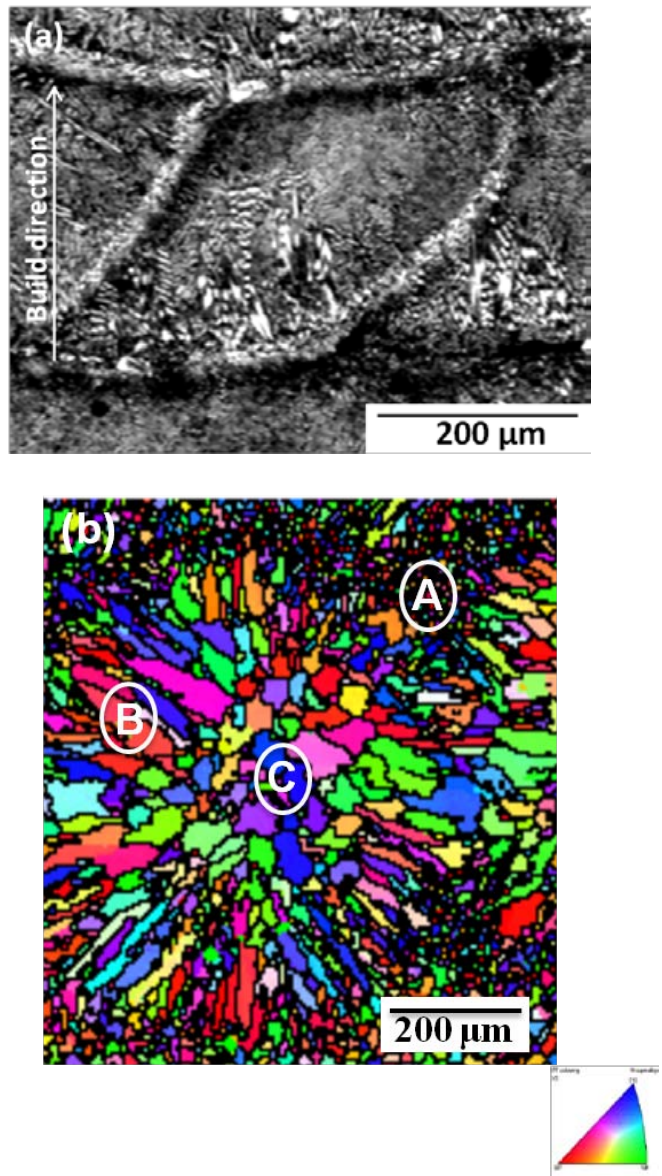

Figure 9. Microstructure of DLFed IN718 in YZ plane, showing (a) an optical micrograph of the bead morphology showing the dendrites (white bands) protruding from the bead boundary to the centre, (b) Inverse pole figure (IPF),map of the bead showing the grain morphology with different regions marked as A, B and C.

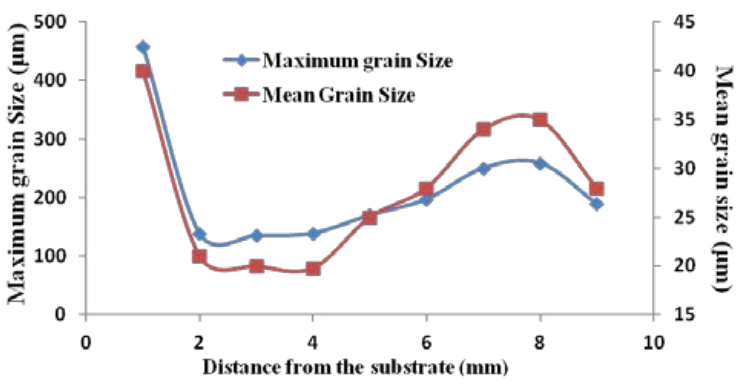

Figure 10. Grain size distribution from top to bottom of the build.

EBSD Mapping

EBSD was performed on the sample to understand the texture and grain morphology, mapping the top plane and showing two deposition passes which were taken from the centre, Fig. 11. The grain structure due to the deposition passes resembles the weld microstructure[14], displaying a generally random texture within 
the build. The columnar grains tend to be oriented along the maximum thermal gradient, which is along the centreline of the moving heat source. The tool path follows a zigzag pattern, where the two passes are in opposite direction to each other (Fig. 4). Each pass is $\sim 500 \mu \mathrm{m}$ wide with an overlap of $300 \mu \mathrm{m}$. This overlap was maintained in order to obtain a defect free build. When the second pass intersects the first pass a re-melted zone is observed.

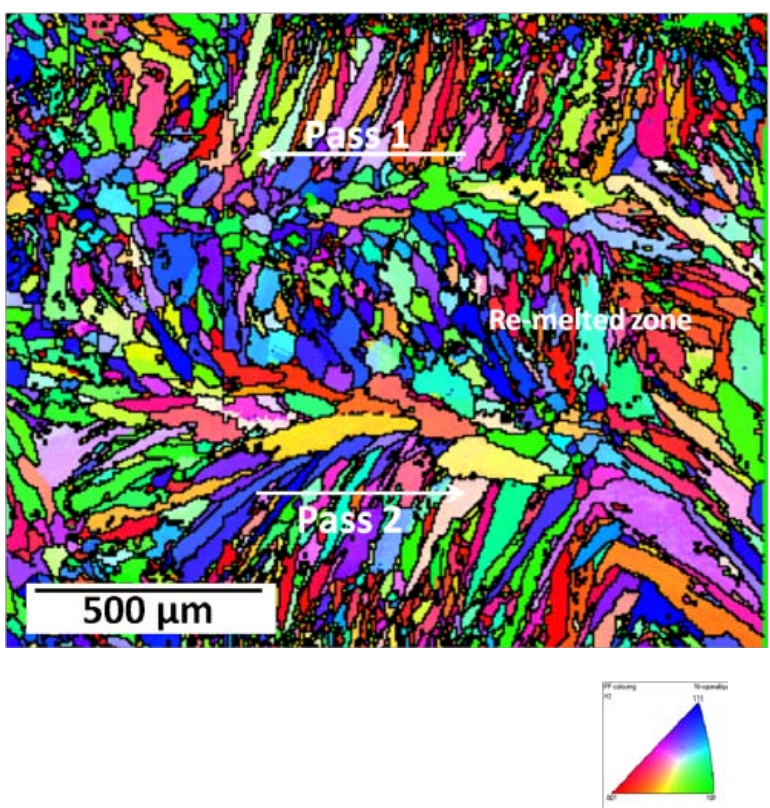

Figure 11. Inverse pole figure (IPF) map of the XY plane (top view) of the build showing the overlap of two passes.

Figure 12 shows the EBSD micrographs of the different planes of the build. From XZ view it can be seen that the deposition has a layered structure with columnar grains growing from the substrate and then an equiaxed band followed by a columnar band again. As we know that the consecutive layers are perpendicular to each other the grains in second layer could be still columnar but looks equiaxed as this layer is seen in a plane perpendicular to the laser beam, in other words the equiaxed zone is the top section of the columnar grains. Based on the EBSD data, a 3D bead-shape model can be generated to visualise the grain morphology in the deposited layers, Fig. 13. The bead possibly has an ellipsoidal shape, based on the microstructural observations (Fig. 9 and 12), which resembles the model suggested by Suutala [15] for the beads formed in stainless steel fusion welds produced using similar speeds $(300 \mathrm{~mm} / \mathrm{min}$ in this case). The fine grains at the edge of the bead look similar to chilled crystals in a casting (region A). As a Gaussian distribution is assumed for the laser beam power in laser deposition, the maximum temperature would be expected to be at the centre of the beam, resulting in the maximum thermal gradient being in the direction from the edge to the centre of the bead. As a result, the first grains to nucleate are the ones along the maximum thermal gradient, growing epitaxially from the bead boundary to the centre (region B in Fig 9). The third region at the centre (region C in Fig 9) seems to be equiaxed zone which was previously observed in aluminium alloy welds [14]. It is expected that as the dendrites grow from bead boundary to centre, solutes will be rejected (as in casting), resulting in nucleation sites, and hence forming the equiaxed grains zone at the centre [8]. But, top view i.e. plane XY (Fig 11) of the build suggests that the grains are not completely equiaxed but has a combination of these and elongated columnar structures.

\section{Grain Selection and Texture}

EBSD mapping was further performed for the side planes of the build and the substrate to visualise the grain morphology and texture, Fig. 12. The large grain at the bottom is the cast substrate, whereas the build itself shows a banded structure, with alternating bands of coarse columnar and fine equiaxed grains. In order to understand the grain selection better, pole figures were plotted at different locations of the build. Microtexture (100) pole figures were constructed from the EBSD data keeping the growth direction (GD) parallel to the deposition direction, Fig. 14. For comparison purposes, the multiples of uniform distribution (MUD) were kept constant at 8 for all the pole plots. Clearly, the substrate is coarse grained, with a strong orientation, Fig. 14-a. Interestingly, the first layer of the build has almost the same texture as the base plate (fig 14-b), but slightly oriented towards the growth direction, which highlights the influence of the substrate grain structure and microtexture on the nucleation of the grain structure in the first layer. Generally, for a cubic crystal, $<100>$ is the favourable growth direction during solidification [16]. Due to this, a slight orientation spread is observed towards the centre. The $\mathrm{n}^{\text {th }}$ layer, which is taken at about the centre of the build, has a fibre texture (fig 14-c), with a weak spread along the $\mathrm{Y}$-axis. Further up in the build, the influence of the substrate texture slowly decreases, and the grains tend to orient along the moving heat source meanwhile growing parallel to the $<100>$ direction giving a fibre texture. The fibre texture was previously observed by Moat et.al in laser fabricated Waspaloy [17]. The MUD of the entire build looks random, with no obvious influence of the base plate texture (fig 14-d). The reason for this is that there is a disruption in the texture from layer to layer because of the changing heat source direction in each pass. In other words the grain orientation in layer $\mathrm{n}$ and $\mathrm{n}+1$ are in opposite direction forming a disruption in texture. 


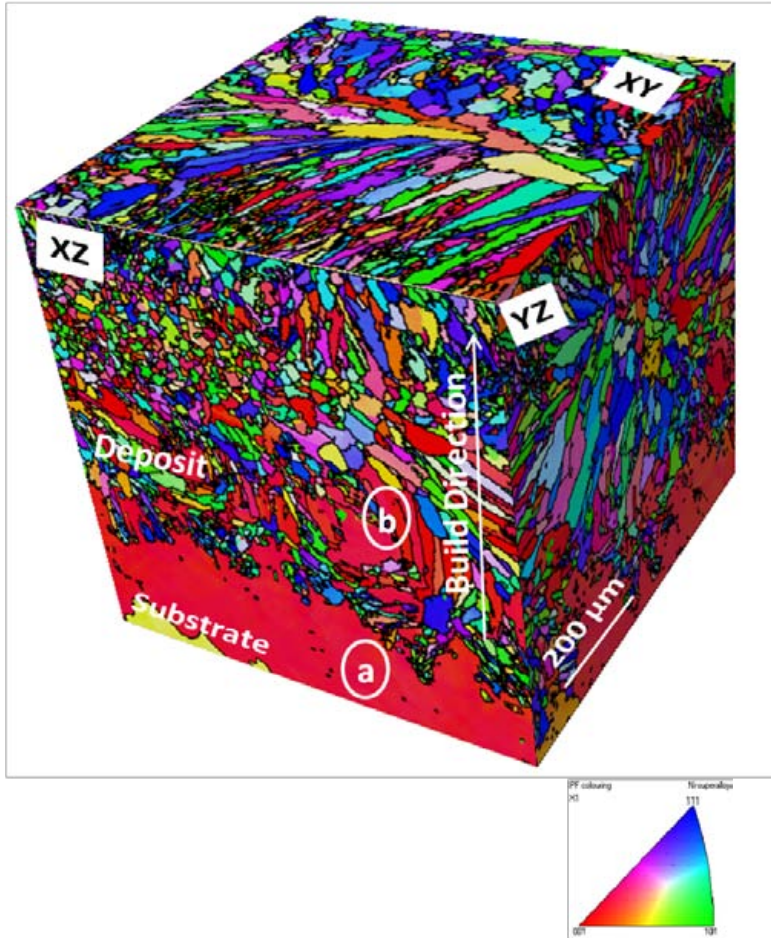

Figure 12. Inverse pole figure (IPF) map showing the $\mathrm{XY}, \mathrm{XZ}$ and YZ planes of the build.

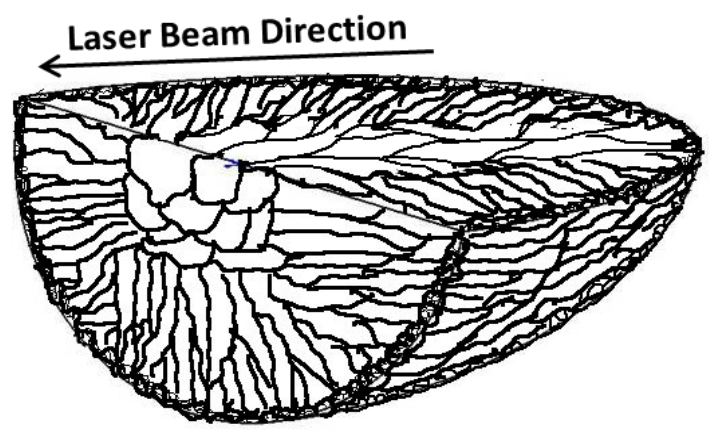

Figure 13. 3D bead morphology
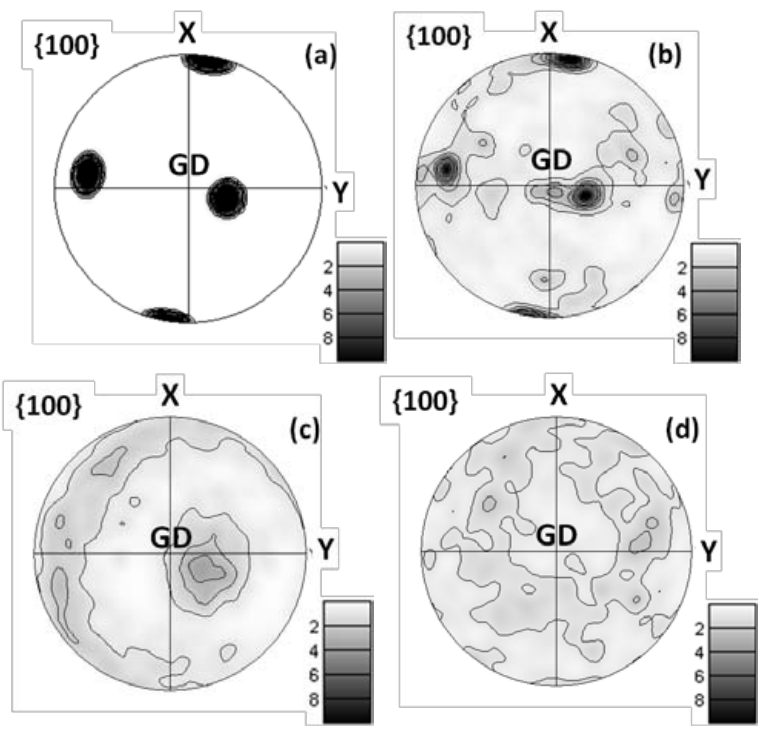

Figure 14. Pole figures showing the multiples of uniform distribution (MUD) at the (a) substrate (b) first layer (c) nth layer (d) overall build (GD represents the growth/build direction).

\section{Precipitation:}

The precipitate distribution and morphologies in the laser deposited samples are quite different from that in the forged IN718 due to the rapid solidification associated with DLF. Microstructural studies were performed for the build to assess the microstructural heterogeneity in the precipitate structure, especially with respect to $\gamma^{\prime} / \gamma^{\prime \prime}$, Laves, and carbide phases. The microstructure generally showed a large degree of segregation within the interdendritic regions, Fig. 15. Three types of precipitates were observed in the build:

A. Square shaped precipitates of size around $1 \mu \mathrm{m}$.

B. Spheroidal shaped precipitates of size 200-300 nm.

C. Irregular shaped precipitates of size $\sim 2-4 \mu \mathrm{m}$.

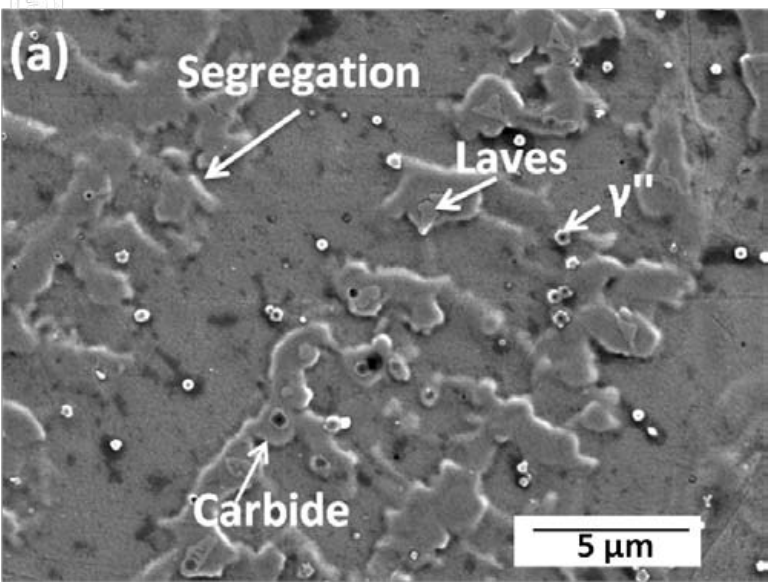



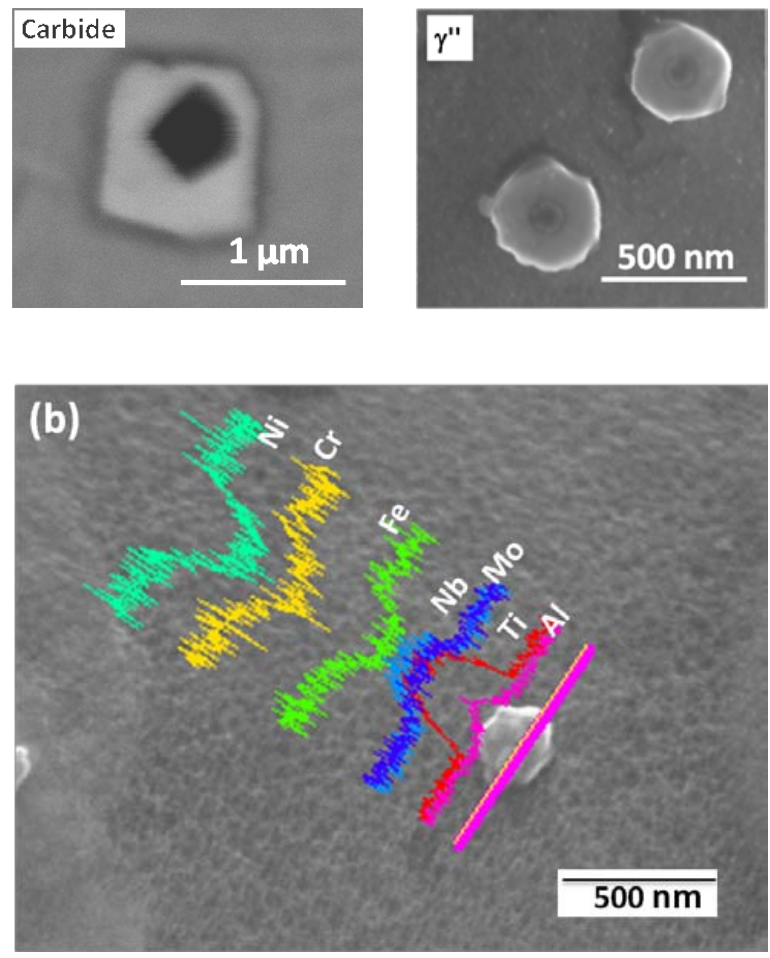

Figure 15. SEM micrograph of the build showing (a) the precipitates (b) Line scan of the $\gamma^{\prime \prime}$ precipitate.

EDS was performed to measure the chemical composition of the phases and within the segregation zones, Table 2. It was found that the segregation zones and the irregularly shaped precipitates were rich in $\mathrm{Nb}$ and $\mathrm{Mo}$; the principal elements of Laves phases. As DLF resembles multi-pass welding, especially with respect to the cooling rates, the solidification process of IN718 welds is often associated with segregation of $\mathrm{Nb}$ and Mo rich phases in the interdendritic regions $[18,19]$. The presence of Laves phases was also observed in DLF structures in IN718 [6].

The square-shaped precipitates are very rich in $\mathrm{Ti}$ and $\mathrm{Nb}$, are likely to be the carbides. The spheroidal shaped precipitates are too small to obtain the composition by point measurements, but were possible using line scans, Fig 15-b. These precipitates are rich in $\mathrm{Nb}, \mathrm{Mo}$, $\mathrm{Ti}$ and $\mathrm{Al}$, which are the principal elements of both $\gamma^{\prime}$ and $\gamma^{\prime \prime}$. From the literature, it is known that the $\gamma^{\prime}$ precipitates are around $200 \AA$ and can be detected only by TEM, whereas the $\gamma^{\prime \prime}$ precipitates are around $1 \mu \mathrm{m}$ in size in spray formed IN718 and can be easily detected by SEM [20]. Thus, it is possible to associate the spheroidal particles with $\gamma^{\prime \prime}$ instead of $\gamma^{\prime}$.

\begin{tabular}{|c|c|c|c|c|c|c|c|c|}
\hline $\begin{array}{c}\text { Predicted } \\
\text { Phases }\end{array}$ & $\mathbf{A l}$ & $\mathbf{S i}$ & $\mathbf{T i}$ & $\mathbf{C r}$ & $\mathbf{F e}$ & $\mathbf{N i}$ & $\mathbf{N b}$ & $\mathbf{M o}$ \\
\hline $\begin{array}{c}\text { Precipitate } \\
\text { (Laves) }\end{array}$ & 0.3 & 0.5 & 1.3 & 14.8 & 13.4 & 47 & 18.4 & 4.3 \\
\hline Carbide & 1.3 & 0.1 & 9.2 & 16.8 & 15.0 & 43.4 & 11.4 & 2.8 \\
\hline Matrix & 0.3 & 0.1 & 0.8 & 19.4 & 18.7 & 53.8 & 3.7 & 3.2 \\
\hline segregation & 0.3 & 0.2 & 1.2 & 17.5 & 16.1 & 51.9 & 9.2 & 3.6 \\
\hline original & 0.29 & 0.14 & 0.9 & 18.2 & 18.9 & 53.34 & 5.1 & 3.1 \\
\hline
\end{tabular}

Table 2. Chemical composition of the precipitates obtained from EDS analysis

\section{Discussion}

Tool path plays a major role in the distortion of the substrate during laser deposition. Tool path should be carefully chosen in such a way that it gives a uniform cooling rate throughout the substrate during deposition. With respect to the build, the porosity can be minimised by parameters optimisation, but it varies significantly across the build. The variation in porosity is due to the variations in the heat dissipation at different locations of the build. The laser power, scan speed and powder flow rate should be changed during deposition to rectify this problem. A high power density at the bottom most layers, where we have maximum heat dissipation, should be applied to minimise porosity at the bottom layers of the build. Though there is fine dendritic structure though out the build, there is non-uniform grain structure and size distribution in the build. On top of banded grain structure few un-melted particles and defects are observed at the bead boundary. This could rise to poor mechanical properties of the build. Blackwell [2] proposed hot isostatic pressing followed by homogenisation heat treatment as a solution to this problem by improving the bonding between layers and homogenising the microstructure thereby improving the mechanical properties. Though there is no strong overall texture, the first few layers select the orientation of the base plate. While looking at each layer a fibre texture is observed around the growth direction due to moving heat source. But, the overall texture can be nullified by choosing a tool path which is perpendicular between layers. The hardness of the deposit (around $280 \mathrm{VHN}$ ) is lower compared to the wrought products which could be either due to large grain size or due segregation of $\mathrm{Nb}$ and the presence of Laves phases instead of sufficient $\gamma^{\prime \prime}$ phase, the major strengthening phase of the alloy. A post deposition heat treatment is recommended to restore the hardness. Homogenisation followed by solution and aging treatments would dissolve Laves phase and precipitate the hardening $\gamma^{\prime \prime}$ and $\delta$ phases to improve the mechanical properties [6].

\section{Summary and Conclusions}

The following conclusions can be drawn from the present work:

1. IN718 superalloy was successfully processed using DLF, with the builds produced being relatively crack-free, consistent with the good weldability of this alloy.

2. The distortion produced is influenced substantially by the tool path, with a correlation found between cooling rate and tool path length.

3. Porosity and bonding defects were observed in the first few layers probably due to the cold substrate causing premature freezing of melt pool and thereby un-melted 
particles; this might be alleviated by faster deposition rate, high power and low powder flow rates in the first few layers.

4. A banded grain structure was observed in the build with the melt pool exhibiting a hemi-spherical shape, with the grains nucleating at the periphery of the melt pool and growing towards its centre in columnar mode.

5. A banded grain structure, with coarse columnar and very fine equiaxed grains, is observed.

6. A disrupted texture is observed in the build with localised texture regions at each layer.

7. The first few layers tended to inherit the orientation of the substrate and there is no influence of the substrate on the subsequent layers.

8. Segregation was observed in the builds with the Nb-rich Laves phase segregating between the layers. Some $\gamma^{\prime \prime}$ and $\mathrm{Ti}+\mathrm{Nb}$-rich carbides were also observed.

\section{Acknowledgements}

One of the authors (LLP) acknowledges support from the Engineering and Physical Sciences Research Council (EPSRC) of the United Kingdom and Rolls-Royce plc, in the form of a Dorothy Hodgkin Postgraduate Award. Helpful discussions with Mr Dan Clark of Rolls-Royce plc are acknowledged.

\section{References}

1. Mazumder, J., et al., Closed Loop Direct Metal Deposition: Art to Part. Optics and Lasers in Engineering, 2000. 34: p. 397-414.

2. Blackwell, P.L., The Mechanical and Microstructural Characteristics of Laser-deposited IN718. Journal of Materials Processing Technology, 2005. 170(1-2): p. 240-246.

3. Qi, H., M. Azer, and P. Singh, Adaptive Toolpath Deposition Method for Laser Net shape Manufacturing and Repair of Turbine Compressor Airfoils. The International Journal of Advanced Manufacturing Technology, 2010. 48(1): p. 121-131.

4. Wu, X., A Review of Laser Fabrication of Metallic Components and of Materials. Materials Science and Technology. 23: p. 631-640.

5. Kobryn, P.A., E.H. Moore, and S.L. Semiatin, The Effect of Laser Power and Traverse Speed on Microstructure, Porosity, and Build Height in LaserDeposited Ti-6Al-4V. Scripta Materialia, 2000. 43(4): p. 299-305.

6. Qi, H., M. Azer, and A. Ritter, Studies of Standard Heat Treatment Effects on Microstructure and Mechanical Properties of Laser Net Shape Manufactured INCONEL 718. Metallurgical and Materials Transactions A, 2009. 40(10): p. 2410-2422.

7. Dinda, G.P., A.K. Dasgupta, and J. Mazumder, Laser Aided Direct Metal Deposition Of Inconel 625 Superalloy: Microstructural Evolution And Thermal Stability. Materials Science and Engineering: A, 2009. 509(1-2): p. 98-104.

8. David, S.A. and J.M. Vitek, Correlation between solidification parameters and weld microstructure. international Materials Reviews, 1989. 34(5): p. 213245.

9. Zhao, H., et al., Three-dimensional finite element analysis of thermal stress in single-pass multi-layer weld-based rapid prototyping. Journal of Materials Processing Technology, 2012. 212(1): p. 276-285.

10. Alimardani, M., E. Toyserkani, and J.P. Huissoon, A $3 D$ dynamic numerical approach for temperature and thermal stress distributions in multilayer laser solid freeform fabrication process. Optics and Lasers in Engineering, 2007. 45(12): p. 1115-1130.

11. Zhao, H., et al., A 3D dynamic analysis of thermal behavior during single-pass multi-layer weld-based rapid prototyping. Journal of Materials Processing Technology, 2011. 211(3): p. 488-495.

12. Zhao, X., et al., Study On Microstructure And Mechanical Properties Of Laser Rapid Forming Inconel 718. Materials Science and Engineering: A, 2008. 478(1-2): p. 119-124.

13. Liu, F., et al., Microstructure and Residual Stress of Laser Rapid Formed Inconel 718 nickel-base superalloy. Optics \& Laser Technology, 2011. 43(1): p. 208-213.

14. T.Ganaha, B.P.Pearce, and H.W. Kerr, Grain Structures in aluminium alloy GTA welds. Metallurgical and Materials Transactions A, 198. 11(8): p. 1351.

15. Suutala, N., Effect of solidification conditions on the solidification mode in austenitic stainless steels. Metallurgical and Materials Transactions A, 1983. 14(1): p. 191-197.

16. K.E.Easterling, Introduction to physical metallurgy of welding1983, Butterworths,London.

17. Moat, R.J., et al., Crystallographic Texture and Microstructure of Pulsed Diode Laser-Deposited Waspaloy. acta materialia, 2009. 57(4): p. 1220-1229.

18. Radavich, J.F. The Physical Metallurgy of Cast and Wrought Alloy 718. in Superalloy 718--Metallurgy and Applications 1989. Warrendale: TMS.

19. Radhakrishna, C.H. and K. Prasad Rao, The Formation And Control Of Laves Phase In Superalloy 718 Welds. Journal of Materials Science, 1997. 32(8): p. 19771984.

20. Azadian, S., et al. Precipitation in Spray-Formed IN 718. in Superalloys $718,625,706$, and Various Derivatives 2001. warrendale: TMS. 